\title{
ЦИФРОВИЗАЦИЯ - ПУТЬ К ПОВЫШЕНИЮ КАЧЕСТВА НАЛОГОВОГО АДМИНИСТРИРОВАНИЯ
}

\section{DIGITALIZATION IS THE WAY TO IMPROVE THE QUALITY OF TAX ADMINISTRATION}

\section{Kobzar-Frolova}

Summary. Tax administration is the daily activity of tax authorities related to tax control and the implementation of the main tasks and functions of tax authorities. The activities of tax authorities in the performance of fiscal and control functions are of strategic importance for the state. When carrying out tax administration, tax officials process arrays of incoming, stored and outgoing information. Without the introduction and use of modern information technologies, this activity will not have the proper effect. The introduction of modern digital technologies in the field of taxes and fees is not an end in itself, but a reality that is consistent with the requirements set by the President of the Russian Federation. The article talks about the plans of the Federal Tax Service of Russia in the field of digitalization, the creation of new information databases, the goals and objectives that they serve. In conclusion, the conclusions corresponding to the study are made.

Keywords: tax administration, digitalization, information technologies, information, digital platforms, tax authorities, tax control, taxpayers, legislation on taxes and fees.

\author{
Кобзарь-Фролова Маргарита Николаевна \\ Д.ю.н., nрофесссор, г.н.С., Институт государства \\ и права Российской академии наук \\ adminlaw@igpran.ru
}

Аннотация. Налоговое администрирование - ежедневная деятельность налоговых органов, связанная с налоговым контролем и выполнением основных задач и функций налоговых органов. Деятельность налоговых органов по исполнению фискальной и контрольной функций имеет для государства стратегическое значение. Осуществляя налоговое администрирование, должностные лица налоговых органов, обрабатывают массивы входящей, хранящейся и исходящей информации. Без внедрения и использование современных информационных технологий эта деятельность не будет иметь должного эффекта. Внедрение современных цифровых технологии в области налогов и сборов - не самоцель, а реальность, которая согласуется с требованиями, поставленными Президентом Российской Федерации. В статье говорится о планах ФНС России в области цифровизации, о создании новых информационных баз данных, целях и задачах, которым они служат. В заключении делаются соответствующие исследованию выводы.

Ключевые слова: налоговое администрирование, цифровизация, информационные технологии, информация, цифровые платформы, налоговые органы, налоговый контроль, налогоплательщики, законодательство о налогах и сборах.

за правильностью исчисления, полнотой и своевременностью внесения в соответствующий бюджет налогов, сборов и страховых взносов [8]. К важнейшим функциональным обязанностям налоговых органов отнесены государственная регистрация юридических лиц, физических лиц (пункт 5.3.1), учет организаций и физических лиц, которые осуществляются в целях проведения налогового контроля (пункт 5.5.1), выявление в ходе налогового контроля фактов недоимок и др.

Деятельность налоговых органов по исполнению фискальной и контрольной функций имеет для государства стратегическое значение. Без внедрения и использование современных информационных технологий эта деятельность не будет иметь должного эффекта. Налоговые органы не смогут добиться требуемых плановых показателей.

Осуществляя налоговое администрирование, т.е. по роду своей ежедневной работы, должностные лица налоговых органов, обрабатывают массивы входящей, 
хранящейся и исходящей информации. Это связано не только с ростом числа налогоплательщиков, но и повышением объема сведений и информации, поступающих от различных организаций, наделенных регистрационными полномочиями, нотариусов, кредитных организаций и иных источников. Вся поступающая информация в электронном или бумажном виде должна быть обработана, систематизирована, взята на учет. И это нужно не только для целей дальнейшего налогообложения, выявления фактов неуплаты, несвоевременной уплаты налогов, сборов, иных платежей, но и для целей формирования информационных ресурсов и др.

Цифра - лишь условный знак, субъективное отражение в сознании человека какого-то события, действия, отражение внешнего мира по отношению к чему-либо большему или меньшему. Человек способен воспринимать цифру и преобразовывать ее в своем сознании. Главное - цифра носитель информации. В правовом мире - цифра позволяет отражать в сознании человека реально существующие правовые явления в форме оценочных отношений к ним и принимать на основе этого восприятия соответствующие решения.

Преобразовывать цифры в информацию человек научился на рубеже XX-XXI вв. Сегодня цифровые технологии позволяют использовать электронно-вычислительные приборы для записи и обработки в определенной последовательности и с определенной частотой поступающие кодовые импульсы [2]. Цифровые технологии становятся благом в том случае, когда с их применением возникает некий эффект, цифровой актив. Например, повышается работоспособность, экономятся трудовые, материальные и иные ресурсы, повышается объем прибыли (доходов), выявляются (не допускаются) ошибки и т.п. Создание цифровых активов современными экономистами рассматривается как важнейший элемент развития цифровой экономики $[14$, С. 8].

Информация как основной компонент единого мирового информационного пространства оказывает универсальное влияние практически на все стороны жизнедеятельности человека, общества и государства. Значение информации в деятельности налоговых органов трудно переоценить.

А.В. Брызгалин современные цифровые технологии в сфере налогов и сборов рассматривает как эффективный элемент финансового механизма [13, с. 8-16]. Он пишет, что внедрение в фискальное налоговое администрирование систем АСК НДС-21, онлайн-касс, сер-

1 Примечание: автоматизированная система контроля за возмещением НДС применяется налоговыми органами с 2013 года. виса «Мой налог», позволило обеспечить исполнение налоговой обязанности самозанятыми. Эффективным образцом модели фискального администрирования, встроенной в хозяйственный оборот налогоплательщика, служит процедура обязательной маркировки товаров средствами идентификации [11].

Внедрение современных цифровых технологии в области налогов и сборов - не самоцель, а реальность, которая согласуется с требованиями, поставленными Президентом Российской Федерации в Стратегии развития информационного общества в РФ на 20172030 гг. При этом, ключевой является задача создания национальных информационных и коммуникационных технологий в целях получения технологических преимуществ использования информации, получения знаний, формирования новых рынков, повышения уровня жизни [14].

Цифровизация налогового администрирования преследует не только внутренние фискальные цели, это путь к мировым цифровым технологиям. Мероприятия налогового администрирования реализуются через сервисно-цифровую модель, обеспечивающую информационное взаимодействие налоговых органов и налогоплательщиков, при этом снижая административное давление на налогоплательщиков.

Всеобщая цифровизация налогового администрирования, интеграция всех источников входящей информации в единую информационную базу данных, обработка информации, ее анализ - прерогатива и целевой ориентир, который Правительство Российской Федерации поставило перед Федеральной налоговой службой (ФНС России). Цифровизация в фискальном администрировании ежегодно дает положительные результаты. А именно, повысилась собираемость налогов, российский предприниматель вынужден «выходить из тени».

По оценке специалистов Boston Consulting Group Россия пока еще серьезно отстает от лидеров цифровой трансформации (Южная Корея, Великобритания, Швеция, Норвегия, Нидерланды и др.). Однако, в части цифровизации фискального налогового администрирования, напротив, стремительно движется к лидирующим позициям [7]. Положительным экономическим эффектом выглядит то, что на наш российский опыт цифровизации налогового администрирования есть спрос и Правительство выражает готовность экспортировать его пакетные решения с целью экономической выгоды для России.

Значимая часть деятельности налоговых органов направлена на выполнение прогнозных показателей, 
заложенных в Основных направлениях бюджетной, налоговой, таможенно-тарифной политики России на 2021 и на плановый 2022 и 2023 годы и, несомненно, осуществляется в целях своевременного и полного поступления доходов от налогового администрирования в бюджет государства и сокращения числа и объема налоговой деликтности [7]. Указанный курс поддерживают многие российские специалисты в области финансового права, полагая, что важнейшей задачей внедрения информационных технологий в сферу налогов и сборов послужит целям неотвратимости исполнения налоговой обязанности в срок и в полном объеме [6. С. 26-33; 9. С. 40-44]. При этом отдельные авторы выражают беспокойство по поводу создания и функционирования информационных баз налоговых органов без надлежащей нормативно-правовой основы, исключительно для фискальной цели [6, с. 26-33]. В этой ситуации методы и формы аналитических мероприятий, которые используют налоговые органы, возможно признать не в полной мере легальными [6. С. 26-33; 9. C. 40-44].

Так, не смотря на пандемию, в 2020 году снижение администрируемых доходов произошло лишь на 7,6\% и снизилось с 22737 млрд. руб. в 2019 году до 21014 млрд. руб. в 2020 году. При этом НДС, НДФЛ, акцизы и имущественные налоги в консолидируемом бюджете страны дали незначительный, но прирост. НДС в 2020 году подрос на 0,3\% по сравнению с 2019 годом, имущественные налоги - на 0,5\%, а НДФЛ за этот же период на - 7,5\% [19]. Существенное снижение показал налог на прибыль предприятий и НДПИ.

В планах ФНС России [3], как основного держателя цифровых технологий в области налогов и сборов, дальнейшее развитие системы налогового администрирования. Так, ФНС России разработан Детальный план-график реализации государственной программы Российской Федерации «Управление государственными финансами и регулирование финансовых рынков на 2020 год и на плановый период 2021 и 2022 годы, который предусматривает следующие задачи, направленные на:

- разработку новых и обновление действующих методик налогового контроля;

- повышение уровня и эффективности собираемости налогов (сборов, страховых взносов), за счет снижения соотношения объема общей задолженности и объема поступлений в бюджетную систему Российской Федерации;

- выявление внутренних и внешних резервов и обеспечение дополнительных поступлений в бюджетную систему Российской Федерации;

- активизацию работ по созданию единого федерального информационного ресурса, позволяю- щего идентифицировать участников правоотношений;

- поддержание уровня и качества предоставления государственных услуг;

- активное развитие риск-ориентированного подхода в вопросах выявления и сокрытия налогооблагаемой базы, в т.ч совершенствование инструментов риск-анализа и повышение уровня дистанционного автоматизированного контроля и др.

Совершенствование системы и инструментов управления рисками направлено на профилактику нарушений законодательства о налогах и сборах и повышение эффективности применяемых форм и методов при проведении риск-ориентированных мероприятий, с оценкой надежности систем внутреннего контроля.

Кроме указанных мер, документ включает обширный перечень мероприятий, основанных на цифровых технологиях, организатором которых должен выступить ФНС России. Так, одним из наиболее глобальных проектов ближайших лет в области налогового администрирования признан проект разработки новой информационной системы АИС «Налог-4» [3]. Это уже четвертое поколение цифровизации налогового администрирования.

В планах фискальной службы, до конца 2021 года внедрить единый федеральный информационный регистр (ФГИС ЕРН). Его цель - получить наибольшее (более 30 видов) количество сведений о каждом гражданине Российской Федерации. Разработчики данного проекта объясняют его важность и значимость тем, что формирование в единой системе подобного информационного регистра будет способствовать сосредоточению массива сведений социального характера. Указанные данные позволят налоговым органам, без предоставления лишних справок и запросов из социальных, регистрирующих и иных служб, предоставлять налоговые вычеты. Например, такие вычеты, без предоставления лишних справок и заполнения непонятных форм, могут быть предоставлены многодетным семьям, малоимущим. Таким образом люди смогут получать адресную материальную и социальную поддержку без лишних проволочек и др. Остается непонятным, почему подобные вопросы переданы в ведение ФНС России, а, например, не Пенсионного фонда Российской Федерации?

Создание ФГИС ЕРН и передача его в ведение ФНС России, кроме указанного, объясняется и тем, что налоговые органы ставят задачу повысить эффективность работы, направленной на борьбу с нарушениями законодательства о налогах и сборах, сократить число 
действий с признаками мошенничества при получении социальной поддержки и налоговых льгот. Это так же позволит повысить профилактическую и предупредительную работу в вопросах уплаты налогов, сборов и других обязательных платежей, повысить собираемости налогов в соответствующие бюджеты бюджетной системы России.

Еще одной из глобальных задач, которые стоят В настоящее время перед налоговыми органами России - создание многопрофильной цифровой платформы по обмену сведениями о налогоплательщике при оказании финансовых и иных услуг - «цифровой платформы оценки налогоплательщика на основе данных ФНС России» и внедрение системы «УСН-Онлайн», предполагающей «легкий старт» и комфортный бизнес. Система позволит вести автоматический учет доходов налогоплательщика в оперативном режиме, при этом отпадет надобность предоставления налоговой декларации для субъектов малого и среднего предпринимательства. Налог будет исчисляться автоматически на основе поступающих в обработку данных. Также в целях эффективной борьбы с нарушением законодательства о налогах и сборах Минфин предложил повысить эффективность анализа за потоками информации о проводимых платежах и совершаемых сделках. Наладить обмен данными между налоговыми органами и банками. В силу статьи 31 Налогового кодекса Российской Федерации в настоящее время налоговые органы вправе требовать от банков только документы, подтверждающие факт списания со счетов налогоплательщика, плательщика сбора, налогового агента и с корреспондентских счетов банков сумм налогов, сборов, пеней и штрафов и перечисления этих сумм в бюджетную систему Российской Федерации;

Подводя итоги работы налоговых органов за 2019 год на заседании Коллегии ФНС РФ было отмечено, что Федеральная налоговая служба - в современных условиях стала крупнейшим агрегатором огромного пула информации, который транслируется в объединенные информационные базы данных государства. Информация, которая сосредоточена в системах ФНС становится источником для аналитики, при осуществлении контроля, надзора, использовании в статистике иными контролирующими органами и органами, для которых информация служит источником составления прогнозов, накопления и систематизации данных для иных целей. На указанном заседании был сделан вывод о том, что амбициозная задача, стоящая перед ФНС России - централизовать разрозненную информацию в единую систему и создать технологическую базу администрирования на годы вперед выполнена. ФНС России завершила внедрение АИС «Налог-3» [20].
На современный период «АИС «Налог-3» - наиболее крупная из всех баз данных зарегистрированных в мире. Ее мощность 705 Тбайт, и этот объем постоянно растет, а главное - обновляется. ФНС России имеет цифровую экосистему, которая позволяет применять современные, ранее не опробированные подходы в налоговом администрировании, собирать аналитику, расширять возможности предупреждения нарушений законодательства о налогах и сборах. Данная система налогового администрирования наиболее адаптирована к трансформации экономики и бизнеса в новой цифровой реальности.

Дальнейшая стратегия ФНС России в области цифровизации администрирования связывается с развитием бесконтактных технологий контроля, без выхода на территорию налогоплательщика. Информационная система «АИС «Налог-3» уже сегодня позволяет перенести акцент из области выездных налоговых проверок к самопроверке и уточнении налогоплательщиками своих налоговых обязательств посредством автоматизированных расчетов. Как показывает практика работы за 2019-2020 год доля самостоятельно проверенных и исправленных налогоплательщиками деклараций растет. Только за 2019 год без проведения выездных налоговых проверок, с посредством применения контрольно-аналитических методов работы в бюджетную систему дополнительно поступило около 90 млрд. рублей [20]. Тем не менее, как указано выше, в планах налоговых органов на ближайшие годы разработка еще более совершенного проекта - новой информационной системы АИС «Налог-4».

Информационные технологии в налоговом администрировании позволяют сдерживать рост налоговой деликтности. Использование цифровых технологий в этом направлении, предполагает наличие определенных требований к собираемой налоговыми органами информации: достоверность, полнота, систематичность, непрерывность, своевременность, обновляемость, доступность машиной обработке. Эффективность использования информации в деятельности налоговых органов зависит от «...ее связи с основными задачами и функциями органа» [1, с. 51-52.]. Между тем, по мнению специалистов [4, С. 17-20], эффективность работы «АИС «Налог-3» снижает: недостоверность поступающей информации, ее недостаточный объем, часто вносимые изменения законодательство о налогах и сборах, не позволяющие быстро и своевременно актуализировать базу данных, нехватка компетентных специалистов в области BigData и IT-специалистов. К этом можно добавить частые технические сбои работы системы, ошибки в настройках, ее сложность.

В 2019 году 4 субъектах Российской Федерации стартовал эксперимент, в рамках которого, запущен 
пилотный проект «самозанятый гражданин». Он основан на передаче информации о продажах и иных доходах от видов деятельности в налоговые органы в автоматическом режиме, освобождение от обязанности составлять отчетность. Старт проекту дал Президент Российской Федерации, подписанием пакета законов, определяющих принципы налогообложения самозанятых граждан [12]. По оценке специалистов Минэкономразвития, на конец 2018 года в России насчитывалось около 16 миллионов лиц, которые не имели официального трудоустройства, но извлекали необлагаемые доходы от видов деятельности [18]. Цель принятия указанного Федерального Закона и введение налога на профессиональный доход [12] - легализовать их деятельность, вывести из тени необлагаемый налогом бизнес, вести учет профессиональных доходов самозанятых.

Эксперимент проводится до 31 декабря 2028 года включительно. Изучение практики действия этого проекта предполагает мониторинг и анализ практики его реализации, после чего можно будет распространить его опыт на все регионы. Реализация указанного проекта поддерживается прикладным программным обеспечением и централизованной ИТ-инфраструктурой, обеспечивающей интеграцию с системами кредитных организаций и операторами электронных баз данных.

Для целей скорейшего внедрения информационных технологий в налоговое администрирование в составе ФНС Минфина России были созданы и успешно функционируют межрайонные инспекции по централизованной обработке данных [5]. Межрегиональные инспекции являются территориальными органами, осуществляющими функции по автоматизированному контролю и надзору за соблюдением законодательства о налогах и сборах, ведению в установленном порядке федеральных информационных ресурсов и информационному обеспечению деятельности ФНС России, органов государственной власти и местного самоуправления, налогоплательщиков в соответствии с действующим законодательством Российской Федерации [10].

Межрегиональные инспекции осуществляют автоматизированную обработку информации; доводят ее информацию до территориальных органов ФНС
России; ведут справочную информацию и классификаторы, а также фонд алгоритмов и программ ФНС России; осуществляют формирование отчетности, архивное хранение информационных ресурсов ФНС России на основе электронных хранилищ данных и централизованное архивное хранение информации; предоставляют в установленном порядке информацию органам государственной власти и местного самоуправления, налогоплательщикам в случаях, установленных законодательством Российской Федерации, обеспечивают обмен информацией в электронном виде с органами государственной власти в соответствии с межведомственными соглашениями. Межрегиональная инспекция ведет: Единый государственный реестр юридических лиц (ЕГРЮЛ), Единый государственный реестр индивидуальных предпринимателей (ЕГРИП), Единый государственный реестр налогоплательщиков (ЕГРН), реестры лицензий, разрешений, свидетельств и иные федеральные информационные ресурсы [10, Раздел II].

Таким образом, цифровизация в налоговой сфере создает предпосылки к преобразованию мер и мероприятий налогового контроля в современные формы, повышает качество и эффективность мер и мероприятий налогового контроля, влияет на снижение налоговой деликтности. Централизованная обработка данных позволяет создать массив полной информации о хозяйственной деятельности налогоплательщиков, т.е. обеспечить решение текущих задач налогового контроля. Применение современных цифровых инструментов в налоговом администрировании позволяет снижать административную нагрузку на сотрудников налоговых органов, автоматизировать процессы обработки данных, предупреждать нарушения законодательства о налогах и сборах, при этом сохранять устойчивые темпы роста поступлений налогов и сборов в доход соответствующих бюджетов. В ближайшей перспективе, информационные технологии в сфере налогов и сборов будут служить интересам реализации государственной социальной политики.

Однако применение цифровых механизмов в налоговом администрировании, требует внесения изменений в действующее законодательство о налогах и сборах и необходимость учесть механизмы его действия при разработке нового кодекса об административных правонарушениях.

\section{ЛИТЕРАТУРА}

1. Бачило И.Л. Функции органов управления (правовые проблемы оформления и реализации).— М., 1976. — C. 51-52.

2. ГОСТ Р 33.505-2003. Государственный стандарт Российской Федерации. Единый российский страховой фонд документации. Порядок создания страхового фонда документации, являющейся национальным научным, культурным и историческим наследием» (принят и введен в действие Постановлением Госстандарта России от 29.07.2003 № 255-ст). 
3. Детальный план-график реализации государственной программы Российской Федерации «Управление государственными финансами и регулирование финансовых рынков на 2020 год и на плановый период 2021 и 2022 годов// Режим доступа: Официальный сайт Министерства Финансов Федерации: Дата обращения 1.07.2021.

4. Ефремова Т.А. Цифровизация налогового администрирования в России: проблемы и перспективы // Налоги. 2021. № 1. С. 17-20.

5. Кобзарь-Фролова М.Н. Теоретико-правовые и прикладные основы налоговой деликтологии: диссертация д.ю.н., М., 2010, с. 385 -389.

6. Овчарова Е.В. Функции административного принуждения в механизме правового регулирования налогообложения и сборов // Административное право и процесс. 2019. № 11. С. 26-33.

7. Основные направления бюджетной, налоговой и таможенно-тарифной политики на 2020 год и на плановый период 2021 и 2022 годов: утв. Минфином России // Официальный сайт Министерства Финансов Федерации: Дата обращения 07.06.2021.

8. Постановление Правительства РФ от 30.09.2004 № 506 (ред. от 22.07.2021) «0б утверждении Положения о Федеральной налоговой службе»//Собрание законодательства РФ, 2004, № 40, ст. 3961.

9. Приказ Минфина России от 17.07.2014 № 61н (ред. от 01.02.2021) «0б утверждении Типовых положений о территориальных органах Федеральной налоговой службы»// Российская газета, № 287, 17.12.2014.

10. Распоряжение Правительства РФ от 28 апреля 2018 г. № 792-р (ред. от 08.11.2019) «0б утверждении перечня отдельных товаров, подлежащих обязательной маркировке средствами идентификации» //Собрание законодательства РФ, 2018, № 19, ст. 2773.

11. Федеральный закон от 27.11.2018 № 422-Ф3 (ред. от 08.06.2020)»0 проведении эксперимента по установлению специального налогового режима «Налог на профессиональный доход// Собрание законодательства РФ,2018, № 49 (часть І), ст. 7494.

12. Федорова 0.С., Набиуллина Л.Р., Брызгалин А.В., Ананьина К.С., Васянина Е.Л. Налог на добавленную стоимость: актуальные вопросы из практики налогового консультирования // Налоги и финансовое право. 2020. № 8. С. 8.

13. Указ Президента РФ от 09.05.2017 № 203 «0 Стратегии развития информационного общества в Российской Федерации на 2017-2030 годы»//Режим доступа: СПС КонсультантПлюс. Официальный интернет-портал правовой информации http://www.pravo.gov.ru, 10.05.2017

14. Bolt U. How a Digital-Assets Ecosystem Could Jumpstart an Inclusive Digital Economy. 2019. [Электронный ресурc]. URL: https://internation-albanker.com/ technology/how-a-digital-assets-ecosystem-could-jumpstart-an-inclusive-digital-economy/.

15. Детальный план-график реализации государственной программы Российской Федерации «Управление государственными финансами и регулирование финансовых рынков на 2020 год и на плановый период 2021 и 2022 годов// Режим доступа: Официальный сайт Министерства Финансов Федерации: Дата обращения 1.04 .2021

16. Заседание Коллегии ФНС Российской Федерации от 11 сентября 2019 г. URL: https://www.nalog.ru/rn77/news/activities_fts/9278853/

17. http://gosmetod.ru/article/356082/

18. https://analytic.nalog.ru/portal/index.ru-RU.htm

19. https://kassa.mts.ru/blog/for-business/zakon-0-samozanyatykh-vse-samoe-vazhnoe/

20. https://www.nalog.ru/rn77/news/activities_fts/9278853/.

( С Кобзарь-Фролова Маргарита Николаевна ( adminlaw@igpran.ru ).

Журнал «Современная наука: актуальные проблемы теории и практики» 